\title{
Epidemiology and Pattern of Clubfoot in Enugu, South- East Nigeria
}

\author{
Tochukwu Nze Ugorji ${ }^{1 *}$, Nwakamma James Ifeanyi ${ }^{2}$, kachisicho Theresa Anoliefo ${ }^{1}$ and Faith \\ Worgu Chimanma ${ }^{3}$ \\ ${ }^{1}$ Department of prosthetics and Orthotics, Federal University of Technology owerri, Nigeria \\ ${ }^{2}$ Department of Prosthetics and Orthotics, Federal College of Dental Therapy and Technology, Nigeria \\ ${ }^{3}$ Department of Biomedical Technology, Federal University of Technology Owerri, Nigeria \\ *Corresponding author: Tochukwu Nze Ugorji, Department of Prosthetics and Orthotics, School of Health Technology, Federal \\ University of Technology Owerri, Nigeria.
}

To Cite This Article: Tochukwu Nze Ugorji, Nwakamma James Ifeanyi, kachisicho Theresa Anoliefo, Epidemiology and Pattern of Clubfoot in Enugu, South-East Nigeria. 2020 - 11(2). AJBSR.MS.ID.001619. DOI: 10.34297/AJBSR.2020.11.001619.

Received: 眥 December 04, 2020; Published: 眥 December 15, 2020

\begin{abstract}
Background: clubfoot is a musculoskeletal birth defect of the foot and ankle that affects a lot of children in the world which can pose ambulatory and activity challenges to affected individual when not treated.

Aim: To evaluate the epidemiology and pattern of clubfoot at Enugu, Southeast Nigeria.

Study Design: A retrospective epidemiological study.

Methodology: Ninety-six case notes of patients managed for clubfoot between January 2014 and December 2017. Simple statistical methods like frequency, percentage and mean were used for data presentation and analysis.

Results: Idiopathic clubfoot had highest prevalence of $92 \%$, secondary clubfoot $6 \%$ and positional clubfoot $2 \%$. Male gender had occurrence rate of $56 \%$ and female $44 \%$. Bilateral clubfoot has greater dominance with a prevalence rate of $75 \%$ and unilateral clubfoot $25 \% .16 \%$ responded to plaster cast application without requiring tenotomy, while $84 \%$ did not respond to plaster cast application, but required tenotomy. $10 \%$ had relapses after correction, while $90 \%$ did not have relapses after correction.
\end{abstract}

Conclusion: Clubfoot is a major birth defect in the study area and is more prevalent in male children and in most cases is bilateral, with idiopathic clubfoot dominance.

Keywords: Clubfoot; Epidemiology; Pattern; Prevalence; Enugu; South-east; Nigeria

\section{Introduction}

Clubfoot has been defined as a condition in which a newborn's foot or feet appear to be rotated internally at the ankle [1]. It is a condition affecting the position of foot and ankle joint in such a way that when untreated, it can lead to physical impairment and difficulty in ambulation and functions [2]. Clubfoot is a congenital condition (present at birth) that causes a baby's foot to turn inward or downward. It can be mild or severe and occur in one or both feet. In babies who have clubfoot, the tendons (Achilles tendons) that connect their leg muscles to their heels are too short. These tight tendons cause the foot to twist out of shape giving rise to clubfoot [3]. Clubfoot is one of the leading birth defects to children, which they do not outgrow when neglected not attended to [4]. Clubfoot has been investigated in some African countries and other parts of the world with emphasis on etiology and treatment. Clubfoot presents with soleus muscle atrophy, equinus of the ankle, cavus and adductus of the forefoot, Varus of the heel which can be unilateral or bilateral [4]. In most cases, clubfoot is discovered after the baby is born by physical assessment or visual inspection of the foot or an X-ray of the foot to confirm the position of the bones that make up the foot arch. It can also be discovered in utero during an 
ultrasound, after which nothing can be done to correct until the child is born [5].

Clubfoot can be classified as: positional; resulting from in utero mal positioning, idiopathic; which is when it has no known cause or cannot be linked to any medical cause, secondary; which is when another disease or condition exposed the individual to clubfoot [6]. Some investigations suggest that a good number of adults battle with challenges of untreated/neglected clubfoot in developing countries, especially in some rural places where people do not know that it can be treated [7].

However, some reports had it the etiology of clubfoot cannot be substantiated [4], while some reported habits like smoking and young maternal age $(<23$ years old $)$ to have an associated cause $[4,8,9]$. Some studies maintained that bilateral clubfoot is more prevalent than unilateral clubfoot and some has it that clubfoot has male preponderance than female [7]. It is also widely believed that most clubfoot is idiopathic and present at birth and could be treated with Ponseti method or surgery.

\section{Materials and Methods}

Study Area: The study is a retrospective study conducted at National Orthopaedic Hospital Enugu, Southeast Nigeria. The hospital is the major government Orthopaedic hospital in southeast region of the country and the catchment areas are mostly Enugu, Abakiliki, Nsukka, Afikpo, Okigwe, owerri and Awaka.

Sample Population: A total of 96 clubfoot patients who visited the hospital between January 2014 and December 2017 (4year period) were studied.

Method of Sample Collection: After a due clearance and permission was sort for and obtained from the Chief Medical Director, National Orthopaedic Hospital Enugu, case note of patients who had presented with clubfoot were retrieved from the medical records unit. Relevant information needed for the study like age, gender, feet involved, position of the affected foot and joint were extracted. Patients' privacy was also maintained during the study and folders returned to the medical records after exploring relevant information.

Inclusion Exclusion Criteria: All patients who presented with clubfoot and were treated at the hospital using Ponseti method or/ and tenotomy within the period under review were included.

Statistical Analysis: simple statistical tools like frequency, percentage and mean were used to analyze the data collected.

\section{Results (Tables 1-6)}

Table 1 shows the pattern of clubfoot reviewed in the study, with idiopathic clubfoot having highest prevalence of $92 \%$, followed by secondary clubfoot $(6 \%)$ and positional clubfoot being the least $(2 \%)$.

Table 2 shows gender prevalence of clubfoot, with male preponderance of $56 \%$ and female $42 \%$.

Table 3 shows unilateral/bilateral distribution of clubfoot in the study area. Bilateral clubfoot dominated with a prevalence rate of $75 \%$ and unilateral clubfoot $25 \%$.

Table 4 shows age distribution of patients. Majority of the clubfoot patients presented to the hospital at the age range of 2942 weeks (21.9\%), followed by $57-70$ weeks (16.7\%), 43-56 weeks (14.6\%), 71-84 weeks (11.5\%), 15-28 weeks (10.4), 85-98 weeks (9.3\%), > 112 weeks (7.2\%), 0-4weeks (4.2\%) and 99- 112 weeks $(4.2 \%)$.

Table 5 shows the type treatment that was used to manage the cases presented. $84 \%$ responded to Ponseti method without requiring tenotomy, while $16 \%$ did not respond to plaster cast application and required tenotomy before correction was achieved.

Table 6 shows the cases that had relapses after correction. 10\% had relapses after correction, while $90 \%$ did not have relapses after correction. From the $10 \%$ that had relapses, $7 \%$ were managed conservatively, while $3 \%$ benefited from surgery (tenotomy). $9 \%$ of the relapse cases were bilateral clubfoot patients, while $1 \%$ was unilateral clubfoot patient.

Table 1: Nature of Clubfoot.

\begin{tabular}{|c|c|c|}
\hline Nature of Clubfoot & Frequency & Percentage (\%) \\
\hline Positional & 2 & 2 \\
\hline Idiopathic & 88 & 92 \\
\hline Secondary & 6 & 6 \\
\hline Total & 96 & 100 \\
\hline
\end{tabular}

Table 2: Gender Distribution of Clubfoot.

\begin{tabular}{|c|c|c|}
\hline Gender & Frequency & 56 \\
\hline Male & 54 & 44 \\
\hline Female & 42 & 96 \\
\hline Total & 96 & 100 \\
\hline
\end{tabular}


Table 3: Unilateral/Bilateral Distribution of Clubfoot.

\begin{tabular}{|c|c|c|}
\hline & Frequency & Percentage (\%) \\
\hline Unilateral clubfoot & 24 & 25 \\
\hline Bilateral clubfoot & 72 & 75 \\
\hline Total & 96 & 100 \\
\hline
\end{tabular}

Table 4: Age distribution of patients at the time of presentation.

\begin{tabular}{|c|c|c|}
\hline Age of patients (days) & Frequency & Percentage (\%) \\
\hline $0-14$ & 4 & 1.2 \\
\hline $15-28$ & 10 & 21.9 \\
\hline $29-42$ & 21 & 14.6 \\
\hline $43-56$ & 14 & 16.7 \\
\hline $57-70$ & 16 & 11.5 \\
\hline $71-84$ & 11 & 9.3 \\
\hline $85-98$ & 9 & 4.2 \\
\hline $99-112$ & 4 & 7.2 \\
\hline$>112$ & 7 & 100 \\
\hline Total & 96 & \\
\hline
\end{tabular}

Table 5: Mode of Treatment.

\begin{tabular}{|c|c|c|}
\hline Mode of Treatment & Frequency & Percentage (\%) \\
\hline Ponseti method & 81 & 84 \\
\hline Tenotomy & 15 & 16 \\
\hline Total & 96 & 100 \\
\hline
\end{tabular}

Table 6: Relapses after Treatment.

\begin{tabular}{|c|c|c|}
\hline & Frequency & Percentage (\%) \\
\hline Relapse & 10 & 10 \\
\hline Non-relapse & 86 & 90 \\
\hline Total & 96 & 100 \\
\hline
\end{tabular}

\section{Discussion}

Idiopathic clubfoot dominated in the study with an occurrence rate of $92 \%$, followed by secondary clubfoot $6 \%$. Positional clubfoot had $2 \%$ which could be because the mothers did not go for CTscan during pregnancy or were not informed of the positioning of their babies before delivery. Study carried by Moorthi RN et al. [10] in 2005 reported idiopathic clubfoot as having the highest prevalence $[10,11]$.

The male gender had 56\% occurrences and female $44 \%$. Many research studies done on clubfoot prevalence also reported male gender dominance [6,11-15]. Bilateral clubfoot had $75 \%$ occurrences and unilateral 25\%. Mkandawire also reported high prevalence rate of bilateral clubfoot in Malawi, Africa in 2004 [16]. The result also showed that most clubfoot patients present to the hospital between the ages of 29-56 weeks (1-2 months), with the peak at 29-42 weeks (1-1.5 months) and could be perceived as the age when the clubfoot becomes obvious to the parents. The least number of patients was recorded at the age range of 0-14 weeks and $99-112$ weeks. $84 \%$ of the cases were corrected with plaster casting, while $16 \%$ benefited from tenotomy because casting alone couldn't correct them. There were non-relapse in $90 \%$ of the cases and $10 \%$ had relapses. $84 \%$ of the clubfeet studied were effectively treated with Ponseti method, which accounts for its dominance and acceptability for clubfoot treatment in the area and all over. The relapses recorded after treating the patients with Ponseti method can be as a result of very short achilles tendon that needs elongation or non-compliance of parents/care giver with Ponseti procedures.

\section{Conclusion}

Clubfoot is a major birth defect in the study area and is more prevalent in male children and also affected both feet (bilateral clubfoot) in majority of the cases. Idiopathic clubfoot was seen to have greater dominance than positional and secondary clubfoot. Bilateral clubfoot was seen to have greater relapse tendency and should be given a more serious attention during treatment to avoid 
relapses. The study also supports other studies that have opined that Ponseti method is an effective method of treating clubfoot conservatively because $84 \%$ of the total cases studied were effectively treated with ponseti method, with only $16 \%$ of the cases requiring surgery/further treatments.

\section{Ethical Approval}

Not applicable

\section{Conflict of Interest}

All the authors do not have possible conflict of interest in the study.

\section{References}

1. B W Alderman, E R Takahashi, M K LeMier (1991) Risk indicators for talipes equinovarus in Washington State, 1987-1989. Epidemiology 2(4): 289-292.

2. Tracey HS (2018) Evidence to improve clubfoot services in Africa with Zimbabwe as a case Study.

3. American Academy of Family Physicians (2018).

4. Melissa Palma, Thomas Cook, Julio Segura, Augustin Pecho, Jose A Morcuende (2013) Descriptive epidemiology of clubfoot in Peru: a clinic-based study. Iowa Orthop J 33: 167-171.

5. Mayo Foundation for Medical Education and Research (2012) Clubfoot.

6. M Bronshtein, A Liberson, S Lieberson, Z Blumenfeld (1992). Clubfeet associated with hydrocephalus: new evidence of gradual dynamic development in utero. Obstet Gynecol 79(5): 864-867.

7. NC Mkandawire, E Kaunda (2004) Incidence and pattern of congenital talipes equinovarus(clubfoot) deformity at Queen Elizabeth Central hospital, Banter, Malawi. East and Central Africa Journal of Surgery 9(2): 28-31.
8. Andrea C Skelly, Victoria L Holt, Vincent S Mosca, Beth W Alderman (2002) Talipes equinovarus and maternal smoking: a population-based case-control study in Washington State. Teratology 66(2): 91-100.

9. B W Alderman, E R Takahashi, M K LeMier (1991) Risk indicators for talipes equinovarus in Washington State, 1987-1989. Epidemiology 2(4): 289-292.

10. Ranjani N Moorthi, Syed Shahrukh Hashmi, Peter Langois, Mark Canfield, D Kim Waller, et al. (2005) Idiopathic talipes equinovarus (ITEV) (clubfeet) in Texas. Am J Med Genet 132(4): 376-380.

11. R Byron-Scott, P Sharpe, C Hasler, P Cundy, C Hirte, et al. (2005) A South Australian population-based study of congenital talipes equinovarus. Paediatr Perinat Epidemiol 19(3): 227-237.

12. Martha M Werler, Mahsa M Yazdy, Allen A Mitchell, Robert E Meyer, Charlotte M Druschel, et al. (2013) Descriptive epidemiology of idiopathetic clubfoot. American Journal of Medical Genetics 161A(7): 1567-1578.

13. Ally Murji, Leslie K Proctor, Andrew D Paterson, David Chitayat, Rosanna Weksberg, et al. (2012) Male sex bias in placental dysfunction. Am J Med Genet A 158A(4): 779-783.

14. Vito Pavone, Sebastiano Bianca, Giuseppe Grosso, Piero Pavone, Antonio Mistretta, et al. (2012) Congenital Talipes Equinovarus: an epidemiological study in Sicily. Acta Orthop 83(3): 294-298.

15. L G Danielsson (1992) Incidence of congenital clubfoot in Sweden. 128 cases in 138,000 infants 1946-1990 in Malmo. Acta Orthop Scand 63(4): 424-426.

16. Vijaya Kancherla, Paul A Romitti, Kristin M Caspers, Soman Puzhankara, Jose A Morcuende (2010) Epidemiology of congenital idiopathic talipes equinovarus in Iowa, 1997-2005. Am J Med Genet A 152A(7): 16951700 